\title{
Castleman's Disease: An Orphan Lymphoproliferative Disorder
}

\author{
${ }^{1}$ Pratik Dipak Shah, ${ }^{2}$ Yogendra Chauhan, ${ }^{3}$ Srijon Mukherji
}

\begin{abstract}
Castleman's disease (CD) is a rare, benign disease of unknown cause that induces reactive lymph node hyperplasia. The disease was first defined by Dr Benjamin Castleman. It is an unusual cause of a neck mass. The goal of this paper is to report a rare case of Castleman's disease at unusual site (level IB) and discuss its management.
\end{abstract}

Keywords: Castleman's disease, Benign, Lymph node, Hyperplasia.

How to cite this article: Shah PD, Chauhan Y, Mukherji S. Castleman's Disease: An Orphan Lymphoproliferative Disorder. Int J Head Neck Surg 2015;6(1):20-22.

Source of support: Nil

Conflict of interest: None

\section{INTRODUCTION}

Castleman's disease $(\mathrm{CD})$ was first described by Benjamin Castleman et al who reported 13 cases of mediastinal lymphadenopathy in $1954 .{ }^{1}$ It is an uncommon disease of lymph node hyperplasia and is also known as angiofollicular lymph node hyperplasia, giant lymph node hyperplasia and angiofollicular lymphoid hamartoma. ${ }^{2}$ $\mathrm{CD}$ is an uncommon cause of a neck mass; in only $6 \%$ of the cases reported in the literature is the disease primarily located in the neck. ${ }^{3}$ Two clinical types, unicentric and multicentric, have been described with three histological variants, the hyaline-vascular (HV) type, which comprises $91 \%$ of cases, the plasma-cell (PC) type and the mixed type. ${ }^{4}$ The most prominent sites are the thorax (mediastinum or lung hilum) and abdomen. ${ }^{5}$

\section{CASE REPORT}

A 22-year-old female patient reported to private maxillofacial surgery institute at Kolkata, with complain of

\footnotetext{
${ }^{1,2}$ Surgical Fellow, ${ }^{3}$ Director and Chief Consultant

${ }^{1,3}$ Department of Oral and Maxillofacial Surgery, Calcutta Institute of Maxillofacial Surgery and Research, Kolkata West Bengal, India

${ }^{2}$ Department of ENT, Calcutta Institute of Maxillofacial Surgery and Research, Kolkata, West Bengal, India

Corresponding Author: Pratik Dipak Shah, Surgical Fellow Department of Oral and Maxillofacial Surgery, Calcutta Institute of Maxillofacial Surgery and Research, Kolkata, West Bengal India, Phone: 8100922153, e-mail: pratikdshah.2711@gmail.com
}

painless, solitary swelling over lower right side of face since 3 years. Swelling was insidious in onset which started as a small mass initially and gradually progressed to present size. Clinical examination revealed a well built female patient with right side facial asymmetry due to swelling over right side submandibular region (Fig. 1). There was no evidence of other regional or distant lymphadenopathy or primary tumor. Swelling was soft, mobile, and diffuse in relation to right side submandibular gland. Salivary flow from right side submandibular gland was normal and there was no pain or increase in size of salivary gland during meal time. There was no palpable calculus in right side submandibular duct. Skin over the mass was normal and no compression of surrounding structures was noted. Two years back, ultrasonography of neck was performed which revealed multiple enlarged solid right submandibular nodes measuring up to $2.7 \times$ $1.6 \mathrm{~cm}$. Computed tomographic images with contrast medium enhancement revealed well-defined, oval, moderate to significantly homogenously enhancing lesion in level IB region having approximate size $3 \times$ $2 \mathrm{~cm}$ which was abuting right submandibular gland posteriorly and right ramus of the mandible anteriorly with preserved intervening fat planes (Fig. 2). As fineneedle aspiration lytology is often inconclusive, we did not advise it. Patient did not have any other symptoms, on clinical examination of whole body did not reveal any palpable mass. Patient's hemogram and routine chemistry were completely within normal range and serology were negative. Moreover, right submandibular lymph node was soft, freely movable and nontender. Patient's age was 22 and did not have any habit.

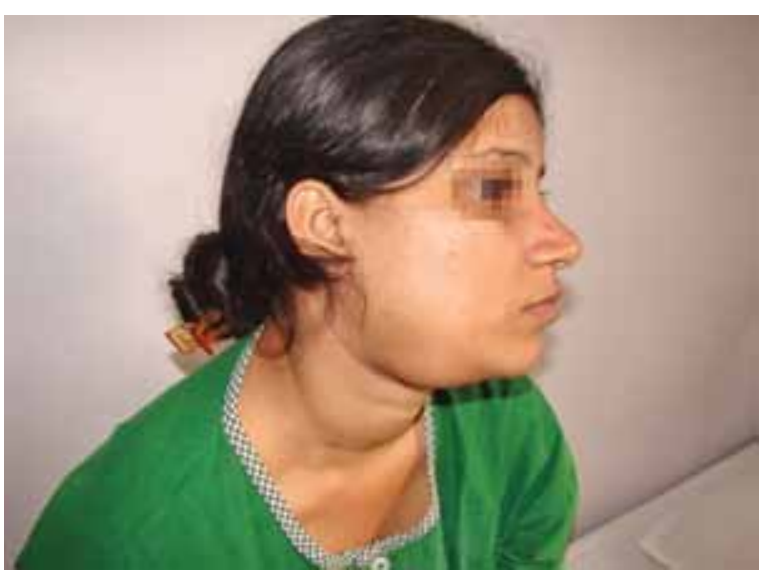

Fig. 1: Right side submandibular (level IB) swelling 
Considering all these factors, we did not suspect systemic involvement, secondary metastasis or any primary elsewhere in the body. We performed a complete excisional biopsy of the lesion through submandibular approach for diagnostic as well as therapeutic purpose. Multiple lymph nodes were involved and lesion was highly vascular (Fig. 3). Histological features of larger nodule showed typical features of hyaline vascular variant of angiofollicular hyperplasia (Castleman's disease) and smaller nodule came as reactive lymphoid hyperplasia (Figs 4 and 5). Castleman's disease has got multicentric variant also which is more common in acquired immune deficiency syndrome. Considering patient's financial constrains and negative serology, and no palpable mass elsewhere in the body, we did not advise whole body scans and asked the patient for long-term follow-up and report at earliest if she finds any palpable mass elsewhere in the body.

\section{DISCUSSION}

Castleman's disease is a rare disorder of lymphoid tissue. As per literature, cervical region is a relatively rare site for

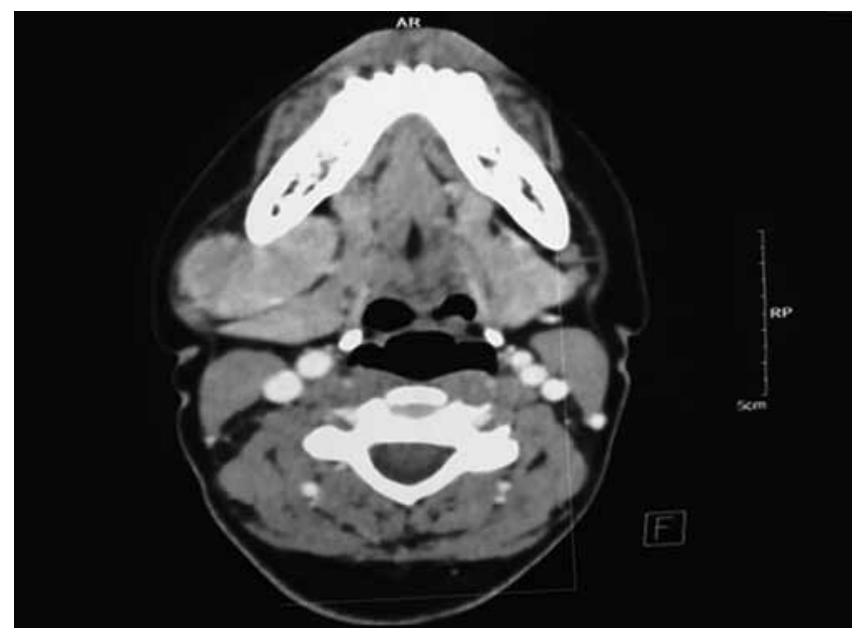

Fig. 2: Enlarged level IB lymph node abuting submandibular gland

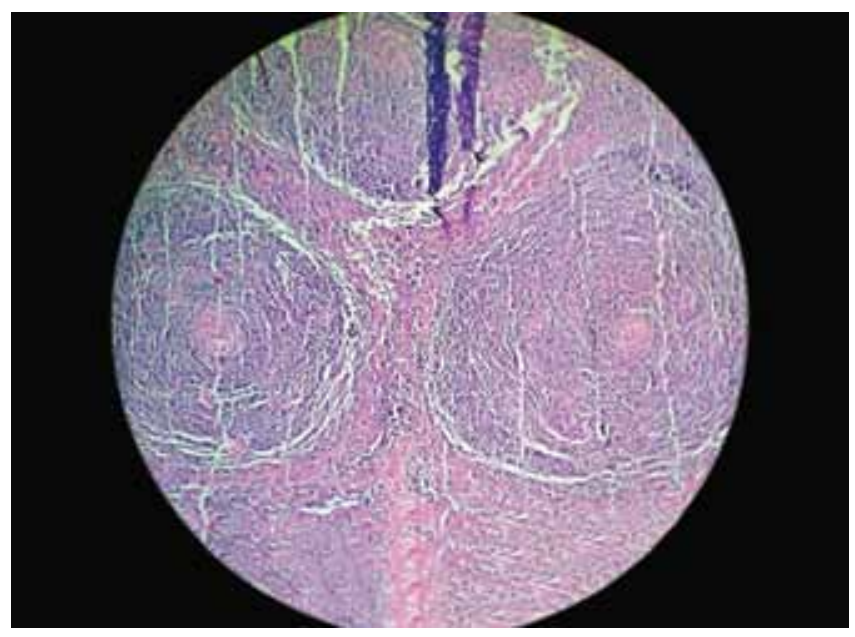

Fig. 4: Interfollicular vascular proliferation this particular disease. Peak incidence ranges from second and third decade without any sex predilection. ${ }^{6}$ The unicentric $\mathrm{HV}$ type is the most common variant encountered clinically. By definition, a single node or chain of lymph nodes is involved which presents asymptomatically except for associated symptoms induced by the mass effect. There have been several reports of patients with multicentric giant cell lymphnode hyperplasia is often seen in patients with acquired immune deficiency syndrome. ${ }^{7}$ In the present case, site, age, variant, clinical symptoms are compatible with those written in previous reports. A key event in the pathogenesis of the disease has recently been suggested to be an abnormal increased production of interleukins; IL- 6 and IL-10. ${ }^{8}$ This leads to lymphoproliferation and plasma cell differentiation and hence carries a risk of progression to lymphoma or plasmacytoma. Plasma cell variety is usually accompanied by various systemic symptoms; they include fever, anemia, elevated ESR and altered plasma protein levels. Histologically, it is characterized by prominent proliferation of small, hyalinized follicles with marked

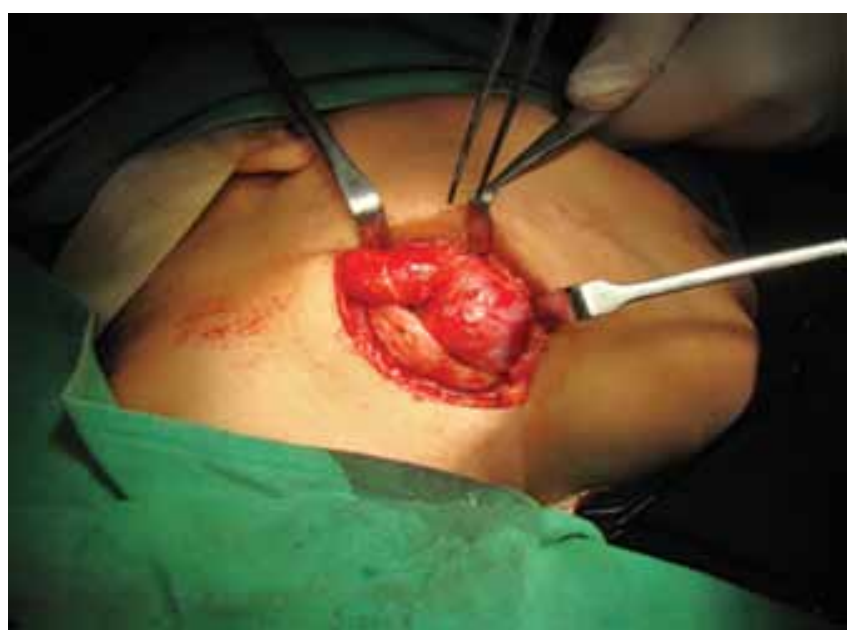

Fig. 3: Enlarged submandibular lymph nodes

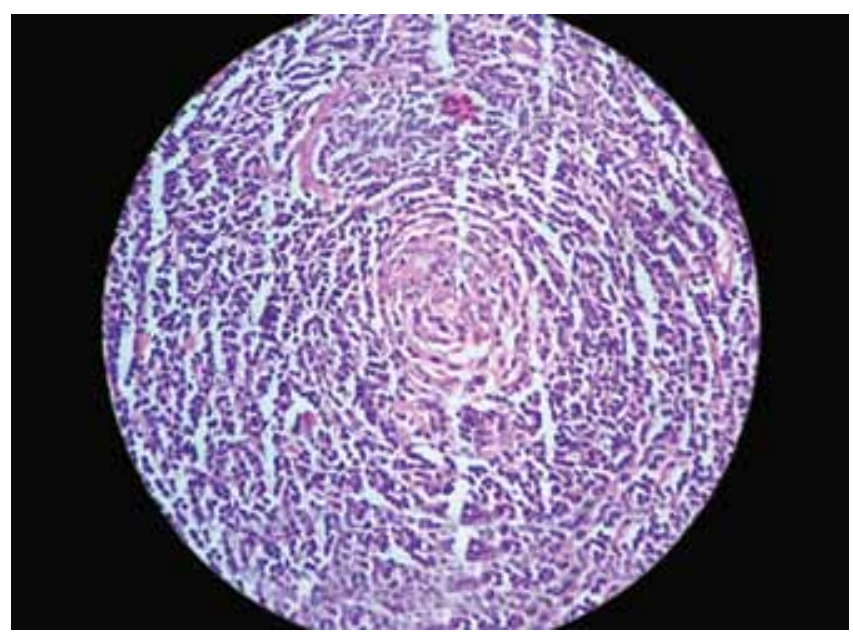

Fig. 5: Involuted germinal center with circumferential concentric small lymphocytic proliferation giving appearance of lollipop 
interfollicular vascular proliferation. The follicles are round and variable in size, surrounded by a cuff of small lymphocytes arranged in concentric 'onion skin' layers, with germinal centers frequently demonstrating atrophy with radically penetrating blood vessels. ${ }^{9}$ Multicentric disease commonly results in death due to infectious complications, multiorgan failure and development of malignancies, such as lymphoma or Kaposi's sarcoma. ${ }^{10}$

\section{CONCLUSION}

Unicentric Castleman's disease is curable with complete surgical excision and with only rare local recurrence. Patients with inoperable tumors, especially the plasma cell type, may benefit from radiotherapy. The role of surgery in multicentric disease, in contrast, is limited. Systemic therapy in the form of corticosteroids or singleor multiple-drug chemotherapies have been used with varied success. ${ }^{10}$

\section{ACKNOWLEDGMENTS}

We wish to acknowledge the colleague who referred this patient to our service and also Dr Srabani Chakrabarti, MD, Pathology, Senior Histopathologist and Laboratory Head, and Dr Mitadru De Sarkar, MD, Pathology, Pathologist, Fortis Hospitals, Anandapur, for their valuable help in diagnosing the disease histopathologically.

\section{REFERENCES}

1. Castleman B, Iverson L, Menendez VP. Localized mediastinal lymph node hyperplasia resembling thymoma. Cancer 1956; 9(4):822-830.

2. Keller AR, Hochholzer L, Castleman B. Hyaline-vascular and plasma-cell types of giant lymph node hyperplasia of the mediastinum and other locations. Cancer 1972;29(3):670-683.

3. Kumar BN, Jones TJ, Skinner DW. Castleman's disease: an unusual cause of a neck mass. ORL 1997;59(6):339-340.

4. Lin CY, Huang TC. Cervical posterior triangle Castleman's disease in a child: case report and literature review. Chang Gung Med J 2011;34(4):435-439.

5. Bowne WB, Lewis JJ, Filippa DA, Niesvizky R, Brooks, Burt $\mathrm{ME}$, Brennan MF. The management of unicentric and multicentric Castleman's disease: a report of 16 cases and a review of the literature. Cancer 1999;85(3):706-717.

6. Rao HG, Street I, Capper R. Unusual location for Castleman's disease. J Laryngol Otol 2009;123(1):e3.

7. Lowenthal DA, Fillippa DA, Richardson ME, Bertoni M, Straus DJ. Generalized lymphadenopathy with morphological features of Castleman's disease in an HIV positive man. Cancer 1987;60(10):2454-2458.

8. Oksenhendler E, Carcelain G, Aoki Y, et al. High levels of human herpesvirus B viral load. Human interleukin-6, interleukin-10 and C-reactive protein correlate with exacerbation of multicentric Castleman's disease in HIV-infected patients. Blood 2000 Sep 15;96(6):2069-2073.

9. Nguyen DT, Diamond LW, Hansmann ML, Alavaikko MJ, Schroder H, Fellbaum C, Fischer R. Castleman's disease: differences in follicular dendritic network in the hyaline vascular and plasma cell variants. Histopathology 1994;24(5):437-443.

10. O’Donnell JL, Henry FP, Kavanagh E, Brennan P, Kay E, Murphy P, Kelly CJ. Unicentric Castleman's disease: a surprising neck mass. Irish J Med Sci 2006 Jan-Mar;175(1):79-80. 